\title{
Importance of Pharmacists as a Front Line Warrior in Improving Medication Compliance in Covid-19 Patients
}

\author{
Y. K. BOKAM*, C. GUNTUPALLI, S. N. K. R. GUDHANTI, R. MANNE¹, R. R. ALAVALA, N. R. ALLAAND S. K. RANAJIT² \\ K L College of Pharmacy, Koneru Lakshmaiah Education Foundation, Guntur-522 502, India, ${ }^{1}$ Department of QA \& QC, \\ Chemtex environmental lab, Texas-77642, USA, ${ }^{2}$ School of Pharmacy, Centurion University of Technology and Management, \\ Odisha 767001, India.
}

\section{Bokam et al.: Importance of Pharmacists as a Front Line Warrior in Covid-19 Patients}

\begin{abstract}
To explore the effect of clinical pharmacist intervention on the treatment of viral pneumonia with intravenous methyl prednisolone and others. The clinical data of 112 patients from July 2020 to September 2020 were categorized into observational group $(n=56)$ and random group $(n=56)$ according to the randomized double blind method. The control group with routine nursing intervention and the observational group was treated with comprehensive clinical pharmacist and nursing intervention. Quality of life, recovery time and saturation levels were assessed frequently and on a weekly basis. The observational group was found to have improved oxygen saturation levels during frequent evaluation with the saturation probes when compared with control group, as well the recovery time was also improved. The quality of life in the observation group was significantly better than that in the control group. Incorporating a clinical pharmacist as an integral member of the health care team, brings numerous benefits, one among them is significant improvement in the delay drug administration to the patient. It is undeniable that a clinical pharmacist is a drug information resource for all the health professionals working in a hospital setting.
\end{abstract}

Key words: Methylprednisolone, comprehensive monitoring, neuropsychiatric, co morbidities, prescription audit

Since January 2020, when the World health organization (WHO) declared corona virus disease 2019 (Covid-19) as a health emergency, human life has become unpredictable. With an abrupt increase in the number of cases, nations across the globe started to impose shut down's to impede the spread of infections with a view to protect their citizens ${ }^{[1]}$. Initially the esteemed organization's such as WHO, released statement that Covid-19 is not devastating and it doesn't spread within humans. Sooner or later in a short period of time, the institute has again reclaimed that the Covid-19 is a novel infection, which the world has never witnessed before and is highly contagious. Both the above contradictory statements led to creation of an ambiguity in the peoples mind, what to believe and what not to believe. However, the infection continued to spread widely which overburdened the health care system at a certain point. Here comes the significance of pharmacist as a front line warrior in managing the pandemic effectively. Hospital pharmacists and clinical pharmacists (CP) played a vital role. Being a front line warrior, it's hard enough to confront the infection ${ }^{[2,3]}$.

*Address for correspondence E-mail: yernikumarb@gmail.com

March-April 2021
The role of hospital pharmacists comes with many huge responsibilities, one among them is calculating the dose as per the prescription and dispense the correct number of pills, especially in the case of favipiravir an antiviral drug. Managing the huge crowd is another challenging task in the meanwhile, pharmacist must ensure that physical distancing is maintained by everyone and mask is worn while standing at the pharmacy counter. It is not just a single pill, multiple medications which include doxycycline, prednisolone, ivermectin, anticoagulants and immune boosters are also to be dispensed at one time and for the art of dispensing, pharmacist must be skilled. Unfortunately in the real scenario, the term skilled pharmacists is merely a theoretical thing, as majority of the pharmacists who are working in this pandemic time are fresher's with

This is an open access article distributed under the terms of the Creative Commons Attribution-NonCommercial-ShareAlike 3.0 License, which allows others to remix, tweak, and build upon the work non-commercially, as long as the author is credited and the new creations are licensed under the identical terms Indian J Pharm Sci 2021;83(2):398-401 
impartially equipped with dispensing skills. Anyone who is expected to do the work perfectly has to be trained. The circumstances during the pandemic did not allow the senior staff to train the fresher pharmacists, but the budding pharmacists tried their level best of their potential and dispensed the medications correctly. At a certain point of time, it is the budding pharmacists who were able to dispense effectively at par with their senior, which is really an appreciable deed. Dispensing the correct medicine, correct dose and the correct number of pills is something like a promise beyond prescription $^{[4-6]}$. Despite many hardships, hospital pharmacists put their patient priorities a head and tried to give their best. Amid managing the unexpected pandemic, a few of the prescriptions were not legibly written and few are in cursive hand writing which makes the lives of pharmacist difficult. I mean it is really hard to read and understand the medication orders in the prescription. In this scenario, there is every chance of dispensing error to occur, while senior pharmacists with their sound drug knowledge were able to understand the prescription and dispense the medicine correctly. Alongside, the budding pharmacists were being mentored by the seniors. Instructing the patients to stand apart from each other with a minimum of six feet distance, use a sanitizer as a preventive measure was made mandatory for anyone who comes to purchase medicines from the pharmacy. Display boards were hanged in and around the hospital premises to bring awareness among everyone $\mathrm{e}^{[7,8]}$. For the smooth functioning of the operations in the hospitals right from patient admission to discharge, the hospital and CP have put relentless efforts for the speedy recovery of the in-patients. Isn't it a selfless sacrifice as pharmacist's put their life at risk to overcome the extraordinary crippling circumstances? However, the organizations also supported all the health care warriors by incentivizing them. The schedule is framed in such a way that each pharmacist gets a leave after every $3 \mathrm{~d}$ prompting them to work more vibrantly. A total of 112 patients infected with viral pneumonia were selected for the study in the infection control ward from
July 2020 to September 2020. The age of the patients ranged from 35 to 58 y divided into two groups and were randomly categorized into observation group $(n=56)$ and control group $(n=56)$. The average age of the observation group was $46.23 \pm 1.85 \mathrm{y}$ old. The age of the control group was 35-56 y old. Patients comprising Covid-19 reporting and data system (CO-RADS), CORADS 4 and CO-RADS 5 accompanied with existing comorbidities fall under inclusion criteria. Patients under the age $35 \mathrm{y}$ and above $58 \mathrm{y}$, with cancer, neuropsychiatric problems were excluded ${ }^{[9]}$. The patients in the control were given care only by the assigned nurse and the treating physician, were not monitored by any other health professional with regard to medication administration. The patients in the observation group were rendered care by the assigned nurse, treating physician and a CP. In-patient prescription audit and monitoring of medication was done by the CP to the patients in this group and patient counseling was also done by one of the health professional. During the ward rounds by $\mathrm{CP}$, the dilution and administration of methyl prednisolone was assessed for the appropriateness of dose. Assessment was done by asking the nurse how much dose $(\mathrm{ml})$ of the drug was administered as per the prescription. In a few instances, CP observed that concerned staffs that were diluting the medicine in the medication preparation area. Speaking about one case, pulmonologist advised $125 \mathrm{mg}$ of methyl prednisolone once a day, of which the vial is present in $500 \mathrm{mg}$ dry powder by manufacturing. As per the instructions mentioned in the leaflet, $500 \mathrm{mg}$ of dry powder should be diluted with $10 \mathrm{ml}$ sterile water and $2.5 \mathrm{ml}$ must be given which will then be equal to $125 \mathrm{mg}$. But unfortunately $5 \mathrm{ml}$ was administered which was almost double the dose prescribed and a few other patients were given less than $2.5 \mathrm{ml}$. Based on the above scenario, it is evident that either overdose or under dose of the drug was administered to the patients in spite of correct dose ${ }^{[10]}$. From Table 1, it can be clearly understood that actual dose intend to be administered was not administered. Only eleven of the sixty patients received the appropriate dose in

TABLE 1: CONTROL GROUP REPRESENTS DOSE ADMINISTERED AND ACTUAL DOSE TO BE ADMINISTERED, ANALYZING WHETHER THE DOSE GIVEN IS OVER DOSE OR UNDER DOSE, (N) REPRESENTS THE NUMBER OF PATIENTS

\begin{tabular}{lcccc}
\hline (N) & Dose prescribed in $\mathrm{mg}$ & Dose given in $\mathrm{ml}$ & To be actually given & Overdose/underdose \\
\hline 24 & 125 & 5.0 & 2.5 & overdose \\
19 & 125 & 4.5 & 2.5 & overdose \\
11 & 125 & 2.5 & 2.5 & correct dose \\
06 & 125 & 2.0 & 2.5 & under dose \\
\hline
\end{tabular}


compliance with the prescription. Majority of the patients received dose more than intended that is, forty three of them received the over dose and six patients received lower than the prescribed dose. Due to overdose, a spike in the blood glucose levels was observed frequently in most of the patients. As a matter of fact, corticosteroids or glucocorticoids enhance the glucose metabolism thus raising the blood sugar levels of the patients. With the rise in plasma glucose levels, it has become inevitable to prescribe higher dose of insulin as a strategy to bring down the sugars to normal. What's more bizarre is patients used to end up with de novo diabetes mellitus. Inappropriate medication adherence, not administering the correct dose intentionally or unintentionally would certainly affect the recovery of patient. In fact the recovery will be delayed. This situation has every possibility of overwhelmingly putting economic burden on the patient's family, eventually landing up in financial debts. With the CP intervention, most of the patients received the correct dose as intended. The above figures in Table 2 indicate the prominence of a $\mathrm{CP}$ in a hospital setting especially during pandemic times. Going further, it has been an immense pleasure and a warm welcome where in, a few hospitals the CP's was assigned the role of duty medical officers. In this role, the CP's will be having an accessibility to communicate with the patients to know their complaints. Isn't this a great practical exposure! The $\mathrm{CP}$ accompanied the general physician as a part of intensive care unit rounds and ward rounds thus making the patient care services more effective ${ }^{[11]}$. The article had mainly focused on intravenous drug dilutions where noncompliance is majorly seen. Fortunately, other intravenous medications such as enoxaparin $60 / 0.6 \mathrm{ml}$ or $\mathrm{mg}$, $40 / 0.4 \mathrm{ml}$ and ceftriaxone $1 \mathrm{~g}$ are available by manufacturing itself which doesn't require any calculation after reconstitution or dilution. These medications in ninety percent of the cases were prescribed as such, as they come in the manufacturing dose, so the chance of administering the correct dose is profound. Medication compliance is higher with such medications unlike medicines such as methyl prednisolone ${ }^{[12]}$. Based on the daily change in saturation values of the patients, dose of Solu-Medrol (Methylprednisolone sodium succinate) also changes, but often in a few instances the previous day dose was found to be administered. The reason includes that there is no daily updation of the change in Solu-Medrol dose from the primary consultant notes to the medication chart by the resident. As a result, the adherence was lacking eventually, the patients didn't get the correct dose of steroid as intended by the treating physician. Here comes the crucial role of $\mathrm{CP}$ in ensuring the right dose administration to the patients. In-patient prescription audit by $\mathrm{CP}$ has led to resolve many discrepancies especially when it comes to diluting and administering the methyl prednisolone. Because the prescribed dose doesn't come by manufacturing, one has to dilute the dry powder drug and administer the required quantity in millilitre as per the medication orders. Appropriate calculation is important to know how much millilitre comprise how much milligram and the CP's have tried hard enough to raise the drug dilutions knowledge as well instructed the nursing staff to check the change in medication orders on daily basis. There are numerous other reasons for the medication non-compliance to occur. As per the National Board of Accreditation for Hospitals and Health Care, one critical patient must be served by one nurse. Soaring number of confirmed cases with mild, moderate and severe category did not allow the health care personnel to abide by the rules framed by National Accreditation Board for Hospitals \& Healthcare Providers (NABH). During the pandemic time, the only prime importance of every health care professional time is to just serve the patients with great compassion thus ensuring patients are recovered at the earliest and discharge them. As the recovered patients are getting discharge slowly, the health care warriors were able to handle the other bunch of patients who got admitted. Having no perfect medicine and an impression that the infection is taking lives away, people in huge numbers rushed to the hospitals which gradually increased the burden on the front line warriors. Because each staff is bound to handle as many number of cases, rise in the stress levels

TABLE 2: REPRESENTS THE ACTUAL DOSE PRESCRIBED, DOSE ADMINISTERED AND CORRELATING THE DOSE GIVEN TO KNOW WHETHER IT IS OVER DOSE OR UNDER DOSE AS PER THE MEDICATION ORDER

\begin{tabular}{cccccc}
\hline $\mathbf{N}$ & Dose prescribed in $\mathbf{m g}$ & Dose given $(\mathbf{m l})$ & To be actually given & CP intervention & Status \\
\hline 26 & 125 & 2.5 & 2.5 & yes & correct dose \\
10 & 125 & 2.8 & 2.5 & yes & over dose \\
21 & 125 & 2.5 & 2.5 & yes & correct dose \\
11 & 125 & 2.5 & 2.5 & yes & correct dose \\
\hline
\end{tabular}


seem obvious. Coping with many patients created a sort of confusion to whom which medicine was administered, which caused exponential rise in the number of medication errors or discrepancies. With rampant use of corticosteroids, antibiotics, anticoagulants and immune boosters, the medication unavailability was found to be a challenging issue. It is disgusting to say that at the peak moment, medicines were sold at double the price of actual cost making the treatment unaffordable. Bringing the treatment cost to an affordable level is imperative and the governments must swiftly take stringent action on institutions charging exorbitant fee for the Covid-19 treatment. If the above action is not done, the primary and community health care centers must provide good infrastructure at par with the private organizations. Nevertheless, the number of students opting health care profession as their career is declining in size year by year, seems to be another major reason for the increase in burden on existing health care profession. On the other hand, it is claimed that growth in terms of financial potential is also slow in this fields ${ }^{[13]}$. To sum up, CP's are just foolish to their dreams and put their heart in serving their patients at the best. They are equipped with sound drug knowledge and skilled in prescription auditing which makes them unique compared to other health care professionals. Not just ensuring the appropriateness of the prescription, they are expected to walk the extra mile such as verifying whether right dose at right time is administered or not which are important in six rights of medication administration ${ }^{[14]}$. Continuous nursing education is important to equip them with solid drug knowledge especially in diluting and administering the correct dose, medicine as prescribed. It is the responsibility of a $\mathrm{CP}$ to act as one of the important mentor for nurses in improving the drug knowledge. By creating rapid awareness by $\mathrm{CP}$, other members of the health care team has worked successfully in improving the immunity levels of the patients, as higher levels of immunity is required to combat the infection. Public health emergencies are totally unpredictable and to confront such tough circumstances, the whole team of health care professionals is required. Team effort has proven in many instances in bringing out the best outcomes. As well, the role of $\mathrm{CP}$ seem to be indispensable in the pandemic times, ensuring that the right medicine at right time goes to the patient.

\section{Acknowledgements:}

This work was supported by Medicover group of hospitals of India.

\section{Conflict of interests:}

The authors declared no conflict of interest.

\section{REFERENCES}

1. $£ 300$ million announced for community pharmacies to support them during coronavirus outbreak. Department of Health and Social Care, UK Government; 2020.

2. Coronavirus/Covid-19 preparedness. International Pharmaceutical Federation; 2020.

3. Press Release-Community pharmacists in the frontline in the fight against the novel coronavirus disease (Covid-19). Pharmaceutical Group of European Union; 2020.

4. Coronavirus (Covid-19) Pharmacist updates and information. Royal pharmaceutical society; 2020.

5. Guidelines for workplace of Covid-19 case. National Centre for Disease Control; 2020.

6. Covid-19: guidance for supported living provision (Department of Health and Social Care, UK). LTC Responses to Covid-19, International Long-term Care Policy Network (ILPN); 2020.

7. Pharmacist Prescribing: "Test and Treat". National Alliance of State Pharmacy Associations (NASPA); 2019.

8. Advancing team-based care through collaborative practice agreements. Centers for Disease Control and Prevention; 2019.

9. Ourth H, Groppi J, Morreale AP, Quicci-Roberts K. Clinical pharmacist prescribing activities in the Veterans Health Administration. Am J Health Syst Pharm 2016;73(18):140615.

10. Shah TK, Tariq T, Phillips R, Davison S, Hoare A, Hasan SS. Health care for all: effective, community supported, healthcare with innovative use of telemedicine technology. J Pharm Policy Pract 2018;11:3.

11. Parthasarathi G, Mahesh PA. Medication adherence. In: Parthasarathi G, Nyfort-Hansen K, Nahata MC, editors. A text book of clinical pharmacy practice. Chennai: Orient Longman Private Limited; 2004 .p. 54.

12. Osterberg L, Blaschke T. Adherence to medication. N Engl J Med 2005;353(5):487-97.

13. Rimmer A. Covid-19: GPs can stop health checks for over $75 \mathrm{~s}$ and routine medicine reviews. Br Med J. 2020;368:m1157.

14. Hughes CM, Hawwa AF, Scullin C, Anderson C, Bernsten CB, Bjornsdottir I, et al. Provision of pharmaceutical care by community pharmacists: a comparison across Europe. Pharm World Sci 2010;32(4):472-87. 